\title{
Pre-operative Carboplatin/Paclitaxel Versus 5-Fluorouracil (5-FU)-based Chemoradiotherapy for Older Adults With Esophageal Cancer
}

\author{
MOHAMMED AL-JUMAYLI ${ }^{1,2^{*}}$, KHALIL CHOUCAIR $^{3 *}$, AMMAR AL-OBAIDI $^{4}$, \\ ROBIN PARK ${ }^{5}$, AJAY BANSAL $^{6}$, JOAQUINA BARANDA $^{1}$, WEIJING SUN $^{1}$ and ANWAAR SAEED ${ }^{1}$ \\ ${ }^{1}$ Department of Medicine, Division of Medical Oncology, \\ Kansas University Cancer Center, Kansas City, KS, U.S.A.; \\ ${ }^{2}$ Department of Medicine, Division of Hematology/Oncology, \\ South Florida University/Moffit Cancer Center, Tampa, FL, U.S.A.; \\ ${ }^{3}$ Department of Medicine, Kansas University School of Medicine, Wichita, KS, U.S.A.; \\ ${ }^{4}$ Department of Medicine, Division of Hematology/Oncology, \\ University of Missouri-Kansas City, Kansas City, MO, U.S.A.; \\ ${ }^{5}$ MetroWest Medical Center/Tufts University School of Medicine, Framingham, MA, U.S.A.; \\ ${ }^{6}$ Department of Medicine, Division of Gastroenterology and Hepatology, \\ University of Kansas Medical Center and Kansas Cancer Institute, Kansas City, KS, U.S.A.
}

\begin{abstract}
Background/Aim: This study aimed to compare the efficacy and tolerability of pre-operative platinum $/ 5$ fluorouracil $(P 5 F)$ and carboplatin/paclitaxel $(C P)$, in combination with radiation therapy in older adults with locally advanced, stage I-III esophageal cancer. Patients and Methods: We retrospectively reviewed 51 patients aged $\geq 70$ years who underwent chemoradiotherapy followed by esophagectomy for stage I-III esophageal cancer between 2008 and 2018. Pathological complete response ( $p C R)$ and survival rates were compared across the two chemotherapy regimen arms. Results: Treatment completion ( $p=0.28), p C R$ $(p=0.89)$, and partial response rates were similar across both chemotherapy groups. Overall survival (OS) and disease-free survival (DFS) were similar across both groups with $H R=0.80(p=0.62)$ and $H R=0.72(p=0.72)$ respectively. Conclusion: The lesser toxic $C P$ regimen may be used in older patients with locally advanced esophageal cancer,
\end{abstract}

This article is freely accessible online.

*These Authors (MA and KC) contributed equally to this study.

Correspondence to: Anwaar Saeed, MD, Department of Medicine, Division of Medical Oncology, Kansas University Cancer Center, Kansas City, KS 66205, U.S.A. Tel: +1 9135886077, e-mail: asaeed@kumc.edu

Key Words: Esophageal cancer, geriatric oncology, trimodality therapy, platinum/5-fluouracil, carboplatin/paclitaxel. with tumor response and survival rates similar to P5F chemotherapy.

Esophageal cancer (EC) is the $7^{\text {th }}$ most common cancer worldwide and the $6^{\text {th }}$ most common cause of death from cancer (1). Even after curative surgical treatment, the prognosis of EC remains poor with a 5-year survival rate of nearly $40 \%$ (2).

Although there is currently no global consensus (3), preoperative treatment with chemoradiotherapy (CRT) followed by esophagectomy is an accepted standard of care for managing locally advanced esophageal cancer in the United States (US) and Europe $(4,5)$. Multiple trials and meta-analyses have established the superiority of a trimodality approach involving CRT followed by esophagectomy, to surgery alone or radiation therapy, in terms of achieving complete pathologic response (pCR) and significant increase in survival (6-10).

EC incidence is particularly rising in the geriatric population with a median age of diagnosis of 65 years (1). This is of particular concern in Western countries where the overall life expectancy has improved. In the US alone, 17,650 new EC cases were diagnosed in 2019 (11), and more than $50 \%$ of all EC cases were diagnosed in patients 70 years of age and older (12). Yet, and despite the higher prevalence of EC in the geriatric population, patients 65 years of age or older have historically been substantially underrepresented in cancer clinical trials (13). In older adult patients (>65 years) with EC specifically, the trimodality approach has been distinctively underutilized despite proven significant 
survival benefit and potential for cure with treatment compared to supportive care (14), and the lack of association between age and treatment outcome and complications (15). There is thus a need to better characterize outcomes and toxicities of the trimodality approach in the geriatric population of patients with locally advanced resectable EC.

The optimal neo-adjuvant chemotherapy regimen used as part of the CRT approach has not been well studied, with no randomized studies comparing the two most standard chemotherapy regimens for esophageal cancer: carboplatin/ placlitaxel (CP) and platinum/5-fluorouracil (P5F). Historically, neo-adjuvant $\mathrm{P} 5 \mathrm{~F}$ has since long been the standard of care despite significant grade $3 / 4$ toxicity rates up to $57 \%(5,16-18)$. The CROSS trial demonstrated that neo-adjuvant CP with concurrent radiation therapy resulted in better toxicity profiles (grade $\geq 3$ toxicity rates up to $23 \%$ ) $(10,19)$.

These reports of a less severe toxicity profile and similar efficacy with neo-adjuvant $\mathrm{CP}$ are of particular interest in the geriatric population of patients with resectable, locally advanced EC. In this study, we present the first retrospective comparison of these two chemotherapy regimens in older adult patients with EC, in terms of treatment response and survival outcomes.

\section{Patients and Methods}

Study design and participants. In this Institutional Review Board (IRB) approved retrospective analysis of a prospectively maintained database, we have reviewed the records of patients with histologically confirmed stage I-III EC who received trimodality pre-operative CRT, followed by esophagectomy at the Kansas University Cancer Center between 2008 and 2018. Eligibility criteria for patients included age $\geq 70$ years, histologically confirmed EC (squamous cell or adenocarcinoma) at presentation, good functional status (Eastern Cooperative Oncology Group score/ECOG: 0-1 and Charlson comorbidity score $<1$ ), receipt of pre-operative CRT with chemotherapy consisting of either carboplatin/placlitaxel or 5FU/platinum (cisplatin or oxaliplatin), and subsequent esophagectomy (transhiatal/transthoracic). Patients who received any other chemotherapy regimen, had recurrent disease, presented with distant metastasis, were not fit for surgery or had missing/incomplete treatment data, were excluded. Clinicopathological and follow-up data (including patients' characteristics and treatment outcome) were collected and analyzed, and patients were divided into two groups based on their administered chemotherapy: either carboplatin/ paclitaxel (CP) or Platinum/5-FU (P5F).

Pre-treatment staging. All patients underwent initial pre-treatment staging. This included multi-disciplinary evaluation at the weekly esophageal care conference (medical oncology, radiation oncology, and surgical oncology), blood count and liver function testing, an upper gastrointestinal endoscopy with histologic biopsy and endoscopic ultrasonography (EUS), and computed tomography (CT). Radio-labeled fluorodeoxyglucose (FDG) whole body positron emission tomography (PET) was also performed as part of the pre-treatment staging in all patients.
Treatment groups. Treatment groups consisted of either carboplatin/paclitaxel (CP) or platinum/5-FU (P5F). Decisions regarding the choice of chemotherapy regimen were left to the discretion of the treating medical oncologist and were based on the patient's general condition and available evidence at the time of treatment. The $\mathrm{CP}$ regimen consisted of carboplatin with target area under the curve (AUC) of $2 \mathrm{mg} / \mathrm{ml} / \mathrm{min}$ and paclitaxel at dose of $50 \mathrm{mg} / \mathrm{m}^{2}$, administered at day $1,8,15$ and 29 during radiation therapy (RT). In the P5F group, regimen consisted of either oxaliplatin $\left(85 \mathrm{mg} / \mathrm{m}^{2}\right.$ on days 1,15 and 29$)$ or cisplatin $\left(75 \mathrm{mg} / \mathrm{m}^{2}\right.$ on day 1), and 5-FU (day 1-4) at week 1 and 5 during RT, with two additional courses on week 8 and 11 .

Radiation scheme. Pre-operative RT planning was carried out after direct simulation, based on diagnostic images or $3 \mathrm{D}$ based on treatment planning CT images. A total radiation dose of $41.4 \mathrm{~Gy}$ was given in 23 fractions of 1.8 Gy each, with 4 fractions administered per week.

Surgical resection. All patients included in the study underwent esophagectomy four to eight weeks after CRT by either transhiatal or transthoracic technique, at the discretion of the treating surgeon and according to the location of the primary tumor. Post-operative residual tumor $(\mathrm{R})$ classification and pathologic examination off all surgical resection specimens was performed. Histopathologic examination included descriptions of tumor type (squamous $v s$. adenocarcinoma) and extension, lymph node status $(\mathrm{N})$ and resection margin (R). Complete resection (R0) refers to microscopically tumor-free margin, pathologic complete response ( $\mathrm{pCR}$ ) refers to absence of residual tumor from surgical specimen, and partial response refers to downstaging of pre-treatment TNM stage.

Outcomes. The primary outcome was pCR rate, defined as absence of residual tumor from surgical specimen. Secondary endpoints included overall survival (OS) and disease-free survival (DFS). OS is defined as the time from start of treatment to death from any cause and DFS refers to the time from start of treatment to the date of confirmed clinical/radiological progression or death from any cause.

Statistical analysis. For comparisons by chemotherapy group, Chisquared tests were performed for categorical variables. Multivariable logistic regression was used to analyze pCR rates. OS and DFS were estimated for the two chemotherapy groups in the bivariate setting using the Kaplan-Meier method, while Cox proportional hazards models were utilized to estimate the adjusted hazard ratios. Analytical models were adjusted for age, stage, radiation dose, histology sub type, and time interval from completion of neo-adjuvant therapy to surgery. A $p$-Value $<0.05$ [95\% confidence interval $(\mathrm{CI})]$ was considered significant.

Ethics approval and consent to participate. The study was performed in accordance with the ethical standards at the Kansas University Medical Center

\section{Results}

Patients and baseline characteristics. Between 2008 and 2018, a total of 647 patients were diagnosed with stage I-III EC, of whom 204 were above 70 years of age or older. Of those, 51 patients were identified for having undergone 


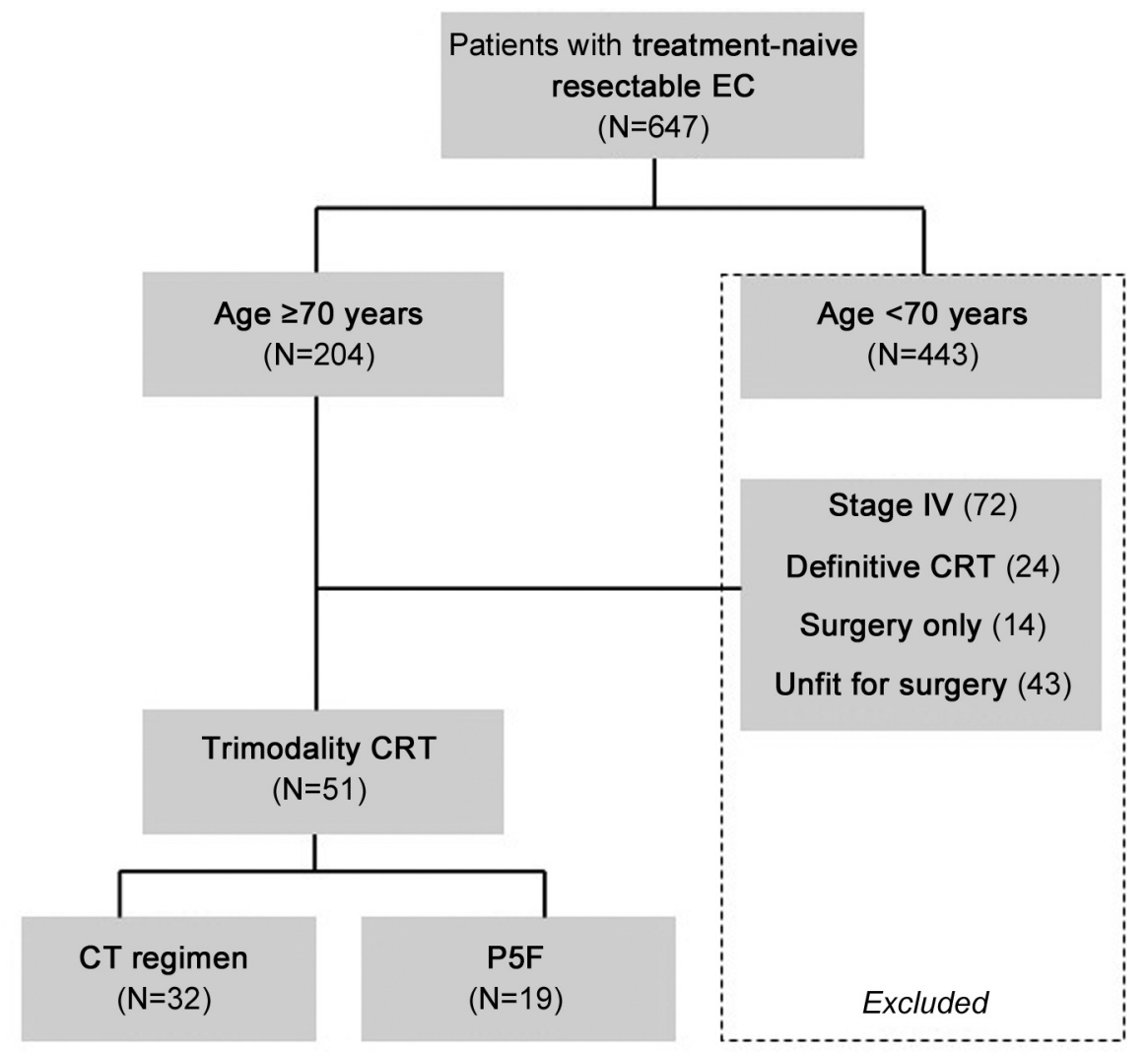

Figure 1. Study schema. A retrospective review of the Kansas University Cancer Center database identified 647 treatment-naive patients with esophageal cancer (EC), of who 204 were 70 years or older. Of those, 51 met inclusion criteria for receipt of trimodality chemoradiotherapy (CRT), and 32 received carboplatin/placlitaxel $(C P)$ chemotherapy while 19 were treated with platinum/5-FU (P5F) chemotherapy.

trimodality pre-operative CRT with the chemotherapy regimen of interest (32 received $\mathrm{CP}$ and 19 received $\mathrm{P} 5 \mathrm{~F}$ ), followed by esophagectomy, and were included in our analysis (Figure 1). Characteristics of these 51 patients are summarized in Table I.

The median age at diagnosis was 75 years ( $70-85$ years). Patients were predominantly males (80.4\%), Caucasian (76.5\%), and with adenocarcinoma histology (66.7\%). Tumors were mainly located in the mid $(35.3 \%)$ and distal esophagus $(43.1 \%)$ regions and the majority of patients $(90.2 \%)$ had stage II/III disease at diagnosis. Age $(p=0.08)$, sex $(p=0.097)$, tumor location $(p=0.41)$ and histology $(p=0.84)$ did not differ significantly among treatment groups. While clinical T stages T2 and T3 were more common in the overall cohort $(96.1 \%$ vs. $3.9 \% \mathrm{~T} 1)$, the distribution among both treatment groups was not different $(p=0.70)$. Similarly, N Stage $(p=0.64)$ was comparable between both groups. Overall, the majority of patients were stage II-III ( $90.2 \%$ vs. $9.8 \%$ were stage I) but the difference in distribution of stages across treatment groups was not significant $(p=0.89)$. All patients completed radiation therapy $(50.4 \mathrm{~Gy} ; 28$ fractions $)$ with variable individualized booster doses at the treating radiation oncologist's discretion.

Treatment response and tolerability. Based on the available follow-up information including pathologic/surgical specimen examination, 50 patients (98.0\%) successfully underwent resection with microscopically-negative tumor margins (R0 resection). Overall, a pCR was seen in $27.4 \%$ of patients and partial response was seen in up to $43.1 \%$ of the entire cohort (Table II). Stratified by chemotherapy regimen, the pCR with $\mathrm{CP}$ vs. $\mathrm{P} 5 \mathrm{~F}$ was $28.1 \%$ vs. $26.3 \%$ $(p=0.51)$. Tumor down-staging was achieved for $41.2 \%$ of the study population, $50 \%$ in the CP cohort and $31.6 \%$ in the P5F cohort $(p=0.20)$. Similarly, nodal down-staging was achieved in $46.6 \%$ of patients who received $\mathrm{CP}$ compared to $36.8 \%$ of those treated with P5F $(p=0.48)$.

In patients treated with pre-operative CP, 31 (96.9\%) completed trimodality therapy including CRT and esophagectomy, compared to $17(89.5 \%)$ in the P5F group $(p=0.28)$. Two patients in the P5F group died within 30 days of surgery due to respiratory complications and sepsis, compared to none in the CP group $(p=0.06)$. 
Table I. Patient and treatment characteristics stratified by chemotherapy regimen.

\begin{tabular}{|c|c|c|c|c|}
\hline Patient characteristics & Overall $(n=51)$ & $\mathrm{CP}(\mathrm{n}=32)$ & P5F $(n=19)$ & $p$-Value \\
\hline Age (median; range) & $75(70-85)$ & 75.3 & 70.6 & 0.08 \\
\hline \multicolumn{5}{|l|}{ Gender } \\
\hline Male $(\%)$ & $41(80.4)$ & 28 & 13 & \\
\hline Female $(\%)$ & $10(19.6)$ & 3 & 7 & 0.097 \\
\hline \multicolumn{5}{|l|}{ Race } \\
\hline Caucasian $(\%)$ & $39(76.5)$ & 25 & 14 & \\
\hline African-American (\%) & $9(17.6)$ & 5 & 4 & 0.88 \\
\hline Other $(\%)$ & $3(5.9)$ & 2 & 1 & \\
\hline \multicolumn{5}{|l|}{ Tumor location } \\
\hline Middle (\%) & $18(35.3)$ & 12 & 6 & \\
\hline Distal (\%) & $22(43.1)$ & 15 & 7 & 0.41 \\
\hline GEJ $(\%)$ & $11(21.6)$ & 5 & 6 & \\
\hline \multicolumn{5}{|l|}{ Tumor histology } \\
\hline $\operatorname{SCC}(\%)$ & $17(13.3)$ & 11 & 6 & \\
\hline Adeno $(\%)$ & $34(66.7)$ & 21 & 13 & 0.84 \\
\hline \multicolumn{5}{|l|}{ Stage (AJCC $8^{\text {th }}$ ed.) } \\
\hline I & $5(9.8)$ & 3 & 2 & \\
\hline II-III & $46(90.2)$ & 29 & 17 & 0.89 \\
\hline \multicolumn{5}{|l|}{ T stage (AJCC $8^{\text {th }}$ ed.) } \\
\hline $\mathrm{T} 1 \mathrm{~b}$ & $2(3.9)$ & 1 & 1 & \\
\hline $\mathrm{T} 2, \mathrm{~T} 3$ & $49(96.1)$ & 31 & 18 & 0.70 \\
\hline \multicolumn{5}{|l|}{$\mathrm{N}$ stage (AJCC $8^{\text {th }}$ ed.) } \\
\hline No & $22(43.1)$ & 13 & 9 & \\
\hline $\mathrm{N} 1, \mathrm{~N} 2$ & $29(56.9)$ & 19 & 10 & 0.64 \\
\hline Chemotherapy receipt & $51(100)$ & $32(100)$ & $19(100)$ & 1.00 \\
\hline Completion of RTx (50.4 Gy;28 fx) & $46(90.2)$ & 32 & 19 & 1.0 \\
\hline Trimodality CRT completion & $48(94.2)$ & $31(96.9)$ & $17(89.5)$ & 0.28 \\
\hline Post-operative death (Within 30 days; \%) & $2(3.9 \%)$ & 0 & $2(10.6)$ & 0.06 \\
\hline
\end{tabular}

CP: Carboplatin/paclitaxel; P5F: platinum/5-FU; 5-FU: 5-fluorouracil; GEJ: gastroesophageal junction; SCC: squamous cell carcinoma; Adeno: adenocarcinoma; AJCC: American Joint Committee on Cancer; T: tumor; N: nodal; RTx: radiation therapy; Trimodality CRT: chemoradiotherapy followed by surgery; Gy: Gray; fx: fraction.

Table II. Pathologic response for patients by chemotherapy regimen.

\begin{tabular}{lccrc}
\hline Pathologic response & Overall $(\mathrm{n}=51)$ & CP $(\mathrm{n}=32)$ & P5F $(\mathrm{n}=19)$ & $p$-Value \\
\hline R0 resection (\%) & $50(98.0)$ & $32(100)$ & $18(94.7)$ & 0.19 \\
Complete (pCR) & $14(27.4)$ & $9(28.1)$ & $5(26.3)$ & 0.89 \\
Partial & & & $6(31.6)$ & 0.20 \\
$\quad$ Tumor down-staging & $21(41.2)$ & $16(50.0)$ & $7(36.8)$ & 0.48 \\
$\quad$ Nodal down-staging & $22(43.1)$ & $15(46.6)$ & \\
\hline
\end{tabular}

CP: Carboplatin/paclitaxel; P5F: platinum/5-FU; 5-FU: 5-fluorouracil; R0: microscopically-negative margin; pCR: pathological complete response.

Multivariate logistic regression analysis. The choice of chemotherapy regimen (P5F vs. CP) was not associated with achieving pCR $(\mathrm{OR}=1.17$; 95\% CI: 0.59-2.3; $p=0.51)$. Similarly, the number of days from CRT completion to surgery, the total dose of radiation received, the disease stage (1-2 vs. 3 ), histology (adenocarcinoma vs. squamous cell carcinoma) and receipt of adjuvant chemotherapy, did not associate with
pCR $(p>0.05)$, although lower tumor stages (1-2) revealed a tendency towards a statistically significant difference in $\mathrm{pCR}$ rate in favor of lower stages $(\mathrm{OR}=0.54$; 95\% CI: 0.26-1.08; $p=0.08)$. Table III summarizes these findings.

Survival outcomes. OS was comparable between the P5F group and the $\mathrm{CP}$ group ( $p=0.62$; HR 0.80$)$ with a median 
Table III. Multivariate logistic regression analysis for achieving $p C R$.

\begin{tabular}{llc}
\hline Multivariate analysis & OR (95\% CI) & $p$-Value \\
\hline pCR (n=51) & & \\
\hline Chemotherapy regimen (P5F vs. CP) & $1.17(0.59-2.3)$ & 0.51 \\
Days from CRT to Sx & $0.99(0.97-1.01)$ & 0.66 \\
Total RTx dose & $0.70(0.99-1.0)$ & 0.96 \\
Stage (1-2 vs. 3) & $0.54(0.26-1.08)$ & 0.08 \\
Histology (Adeno $v s$. SCC) & $1.13(0.44-2.91)$ & 0.80 \\
Receipt of adjuvant Chx & $1.50(0.38-2.16)$ & 0.62 \\
\hline
\end{tabular}

OR: Odds ratio; CI: confidence interval; pCR: pathologic complete response; CP: carboplatin/paclitaxel; P5F: platinum/5-FU; 5-FU: 5 fluorouracil; CRT: chemoradiotherapy; RTx: radiation therapy; $\mathrm{Sx}$ : surgery; Chx: chemotherapy; SCC: squamous cell carcinoma; Adeno: adenocarcinoma.

survival of 20 and 32 months respectively (Figure 2A). DFS was also not significantly different between both groups $(p=0.72$; HR 0.72). Median DFS was 18 months in the P5F group and 20 in the $\mathrm{CP}$ group (Figure 2B).

\section{Discussion}

In this study, we described comparable outcomes in terms of pCR, OS and DFS between CP and P5F used as part of preoperative CRT in a geriatric population of patients with EC. Our reported pCR rates as well as median OS and DFS are comparable to recently published results assessing preoperative CRT in EC $(20,21)$. While prior observational studies have reported similar observations in terms of efficacy, this is to the best of our knowledge, the first study to compare efficacy of different types of pre-operative chemotherapy regimens in a geriatric population of patients 70 years or above.

Unlike younger patients, older patients with EC have unique issues pertaining to life expectancy, functional status, vulnerability to treatment-related morbidity, higher likelihood of competing comorbidities, and subsequent concern regarding patient's ability to tolerate chemotherapy, radiation therapy or surgery (22). Yet, while more than $50 \%$ of newly diagnosed EC are older than 65 years of age, the available evidence to guide therapy of EC patients were generated from trials that excluded geriatric patients $(10,13$, 14, 19). For example, in the CROSS trial which established the use of pre-operative CRT as a standard approach for patients with locally advanced EC, the median age of patients was 60 years and no subset analysis for age was provided $(10,19)$. Our study is unique in that it focuses on patients who are $\geq 70$ years of age and reveals no statistically significant difference in $\mathrm{pCR}$ rates or survival rates (OS and DFS) between CP and P5F.

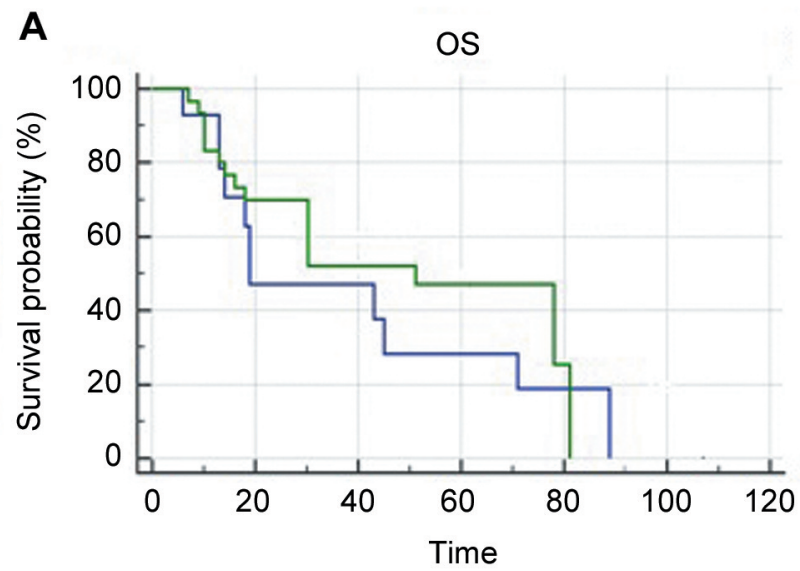

HR $0.8 ; p=0.62$

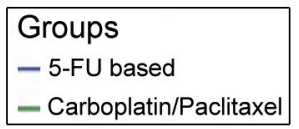

B

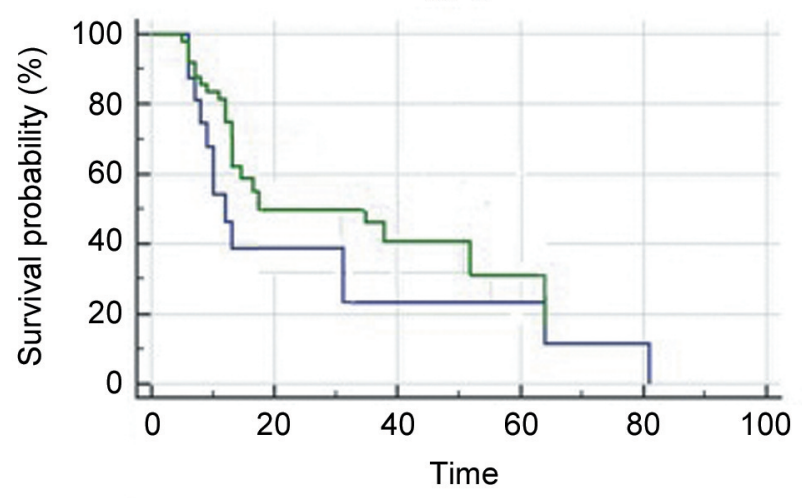

HR $0.72 ; p=0.72$

Figure 2. Kaplan-Meier survival estimation of the overall survival (A) and disease-free survival $(B)$ in months, for CRT with P5F $(n=19)$ or $C P(n=32)$. OS: Overall survival, DFS: disease-free survival, $C P$ : carboplatin/paclitaxel (in green), P5F: platinum/5-FU (in blue), 5-FU: 5-fluorouracil, CRT: chemoradiotherapy, HR: hazard ratio.

Compared to the traditionally used 5FU-based regimens, pre-operative chemotherapy with $\mathrm{CP}$ has been shown to be a more tolerable and less toxic alterative treatment with similar survival outcomes $(18-21,23-27)$. While our study did not include toxicity data, our findings are consistent with published reports of $\mathrm{CP}$ being more tolerable and less toxic than 5FU-based regimen: more patients were able to complete trimodality therapy in the $\mathrm{CP}$ group compared to $\mathrm{P} 5 \mathrm{~F}$, and 2 patients in the $\mathrm{P} 5 \mathrm{~F}$ group experienced post-operative death due to treatment-related sepsis and respiratory complications (Table I). The small numbers in the study pose a challenge to 
drawing solid toxicity conclusions but remains in line with the reported literature. In light of the available literature evidence for toxicity differences that favor $\mathrm{CP}$ over 5FU-based therapies, our work constitutes a proof-of-concept retrospective study that can help guide decision making regarding the choice of a pre-operative chemotherapy regimen that achieves similar efficacy with a better tolerability.

Currently, there is no standardized EC-specific comprehensive geriatric assessment tool that can be used prior to treatment initiation (22). One tool developed by Hurria et $a l$, has been evaluated by the Cancer and Aging Research Group (CARG) in a multicenter prospective study to develop a predictive model for chemotherapy toxicity $(28,29)$. The model identified the following risk factors for chemotherapy associated toxicity: age $\geq 72$ years, gastrointestinal and genitourinary cancers, poly-chemotherapy, anemia, creatinine clearance, as well as geriatric variables such as hearing, number of falls, and functional status. A similar tool called the Pre-operative Assessment of Cancer in the Elderly (PACE) was studied by Audisio et al., and includes a combination of traditional surgical risk assessment along with the comprehensive geriatric assessment (30). The American Society of Clinical Oncology Guideline for Geriatric Oncology currently recommends the use of geriatric assessment in patients $>65$ years to identify vulnerabilities not routinely captured in oncology assessments and obtain estimates of chemotherapy toxicity risk, with either the CARG (Cancer and Aging Research Group) or CRASH (Chemotherapy Risk Assessment Scale for High-Age Patients) (31). Until geriatric EC-specific tools are validated, our study provides evidence that, along with routine geriatric assessment, it could help guide oncologists and patients in a shared decision-making process that takes into account the peculiar vulnerability of the geriatric population, without compromising efficacy and chance of cure.

While we provide a proof of concept for selection of preoperative CRT in the treatment of older adult patients with locally advanced EC, our results should be interpreted with caution given the retrospective nature of the study. Patients were not randomized which could lead to differences in patient characteristics and treatment per treating oncologist between both treatment groups. Another limitation pertains to the single center setting of the study. Lastly, given the retrospective nature of the study, toxicity assessments based on the Common Terminology Criteria for Adverse Events (CTCAE) were not systematically reported, thus hindering inclusion of toxicity data in the study. Similarly, the study did not include a comprehensive geriatric assessment of patients using predictive toxicity tools. While the study was not powerful enough to conduct secondary multivariate analyses for OS and DFS (secondary outcomes), prior studies have shown that for patients with resectable gastric and EC who achieve pCR after neo-adjuvant chemotherapy,
pCR could be a surrogate marker of prolonged survival (OS and DFS) (32).

Our study findings justify a need for future, randomized prospective trials that focus on older adult patients with locally advanced EC, with implementation of a validated Comprehensive Geriatric Assessment (CGA). Such studies are warranted to validate our findings, and to further expand investigation into the development and use of an EC-specific predictive toxicity model, as well as characterizing differences in long term, post-therapy quality of life in this patient population. From a therapeutic strategy perspective, future studies ought to further focus on combinational approaches that can achieve similar efficacy with better tolerability: Immune checkpoint inhibitors are known to be more tolerable than chemotherapy, and their combination with traditional CRT needs to be explored as a strategy that achieves chemotherapy treatment de-intensification in this older adult population. This becomes more relevant in light of the many ongoing studies, and the recent approval of Nivolumab in adjuvant treatment of EC (33).

In conclusion, the present study suggests that $\mathrm{pCR}$ rates, OS and DFS are similar in both treatment regimens. CP could be used as an equally effective, less toxic alternative to $\mathrm{P} 5 \mathrm{~F}$ in older adult patients undergoing pre-operative CRT for locally advanced EC. We report on the first study to compare efficacy of different types of pre-operative chemotherapy regimens in a geriatric population of patients with EC, 70 years or above.

\section{Conflicts of Interest}

AS reports research grant (to institution) from Merck and consulting fees from Merck. WS reports research grant (to institution) from Merck. The remaining Authors declare no competing interests.

\section{Authors' Contributions}

MA and AS developed the study design. MA collected, and interpreted data, and performed statistical analysis. KC performed statistical analysis, made substantial contributions to data interpretation, discussion and drafted the manuscript. AA contributed to drafting of the initial manuscript. AB, RP, JB, and WS contributed to the discussion of the results and review of the manuscript. AS made substantial contributions to conception and design of the study, analyzed, and interpreted data and revised the manuscript. All Authors read and approved the final manuscript.

\section{References}

1 Sung H, Ferlay J, Siegel RL, Laversanne M, Soerjomataram I, Jemal A and Bray F: Global cancer statistics 2020: GLOBOCAN estimates of incidence and mortality worldwide for 36 cancers in 185 countries. CA Cancer J Clin 71(3): 209-249, 2021. PMID: 33538338. DOI: $10.3322 /$ caac. 21660

2 Law S, Kwong DL, Kwok KF, Wong KH, Chu KM, Sham JS and Wong J: Improvement in treatment results and long-term 
survival of patients with esophageal cancer: impact of chemoradiation and change in treatment strategy. Ann Surg 238(3): 339-47; discussion 347-8, 2003. PMID: 14501500. DOI: 10.1097/01.sla.0000086545.45918.ee

3 Sehdev A and Catenacci DV: Perioperative therapy for locally advanced gastroesophageal cancer: current controversies and consensus of care. J Hematol Oncol 6: 66, 2013. PMID: 24010946. DOI: 10.1186/1756-8722-6-66

4 Ajani JA, Barthel JS, Bentrem DJ, D'Amico TA, Das P, Denlinger CS, Fuchs CS, Gerdes H, Glasgow RE, Hayman JA, Hofstetter WL, Ilson DH, Keswani RN, Kleinberg LR, Korn WM, Lockhart AC, Mulcahy MF, Orringer MB, Osarogiagbon RU, Posey JA, Sasson AR, Scott WJ, Shibata S, Strong VE, Varghese TK Jr, Warren G, Washington MK, Willett C, Wright $\mathrm{CD}$ and National Comprehensive Cancer Network: Esophageal and esophagogastric junction cancers. J Natl Compr Canc Netw 9(8): 830-887, 2011. PMID: 21900218. DOI: 10.6004/jnccn. 2011.0072

5 Lordick F, Mariette C, Haustermans K, Obermannová R, Arnold $\mathrm{D}$ and ESMO Guidelines Committee: Oesophageal cancer: ESMO Clinical Practice Guidelines for diagnosis, treatment and follow-up. Ann Oncol 27(suppl 5): v50-v57, 2016. PMID: 27664261. DOI: 10.1093/annonc/mdw329

6 Gebski V, Burmeister B, Smithers BM, Foo K, Zalcberg J, Simes $\mathbf{J}$ and Australasian Gastro-Intestinal Trials Group: Survival benefits from neoadjuvant chemoradiotherapy or chemotherapy in oesophageal carcinoma: a meta-analysis. Lancet Oncol 8(3): 226-234, 2007. PMID: 17329193. DOI: 10.1016/S14702045(07)70039-6

7 Herskovic A, Martz K, al-Sarraf M, Leichman L, Brindle J, Vaitkevicius V, Cooper J, Byhardt R, Davis L and Emami B: Combined chemotherapy and radiotherapy compared with radiotherapy alone in patients with cancer of the esophagus. $\mathrm{N}$ Engl J Med 326(24): 1593-1598, 1992. PMID: 1584260. DOI: 10.1056/NEJM199206113262403

8 Conroy T, Galais MP, Raoul JL, Bouché O, Gourgou-Bourgade S, Douillard JY, Etienne PL, Boige V, Martel-Lafay I, Michel P, Llacer-Moscardo C, François E, Créhange G, Abdelghani MB, Juzyna B, Bedenne L, Adenis A and Fédération Francophone de Cancérologie Digestive and UNICANCER-GI Group: Definitive chemoradiotherapy with FOLFOX versus fluorouracil and cisplatin in patients with oesophageal cancer (PRODIGE5/ACCORD17): final results of a randomised, phase 2/3 trial. Lancet Oncol 15(3): 305-314, 2014. PMID: 24556041. DOI: 10.1016/S1470-2045(14) 70028-2

9 Tepper J, Krasna MJ, Niedzwiecki D, Hollis D, Reed CE, Goldberg R, Kiel K, Willett C, Sugarbaker D and Mayer R: Phase III trial of trimodality therapy with cisplatin, fluorouracil, radiotherapy, and surgery compared with surgery alone for esophageal cancer: CALGB 9781. J Clin Oncol 26(7): 10861092, 2008. PMID: 18309943. DOI: 10.1200/JCO.2007.12.9593

10 van Hagen P, Hulshof MC, van Lanschot JJ, Steyerberg EW, van Berge Henegouwen MI, Wijnhoven BP, Richel DJ, Nieuwenhuijzen GA, Hospers GA, Bonenkamp JJ, Cuesta MA, Blaisse RJ, Busch OR, ten Kate FJ, Creemers GJ, Punt CJ, Plukker JT, Verheul HM, Spillenaar Bilgen EJ, van Dekken H, van der Sangen MJ, Rozema T, Biermann K, Beukema JC, Piet AH, van Rij CM, Reinders JG, Tilanus HW, van der Gaast $A$ and CROSS Group: Preoperative chemoradiotherapy for esophageal or junctional cancer. $\mathrm{N}$
Engl J Med 366(22): 2074-2084, 2012. PMID: 22646630. DOI: $10.1056 /$ NEJMoa1112088

11 Vajravelu RK, Kolb JM, Thanawala SU, Scott FI, Han S, Singal AG, Falk GW, Katzka DA and Wani S: Characterization of prevalent, post-endoscopy, and incident esophageal cancer in the United States: A large retrospective cohort study. Clin Gastroenterol Hepatol, 2021. PMID: 33549872. DOI: 10.1016/ j.cgh.2021.02.005

12 Fan J, Liu Z, Mao X, Tong X, Zhang T, Suo C and Chen X: Global trends in the incidence and mortality of esophageal cancer from 1990 to 2017. Cancer Med 9(18): 6875-6887, 2020. PMID: 32750217. DOI: 10.1002/cam4.3338

13 Hutchins LF, Unger JM, Crowley JJ, Coltman CA Jr and Albain KS: Underrepresentation of patients 65 years of age or older in cancer-treatment trials. N Engl J Med 341(27): 2061-2067, 1999. PMID: 10615079. DOI: 10.1056/NEJM199912303412706

14 Molena D, Stem M, Blackford AL and Lidor AO: Esophageal cancer treatment is underutilized among elderly patients in the USA. J Gastrointest Surg 21(1): 126-136, 2017. PMID: 27527093. DOI: $10.1007 / \mathrm{s} 11605-016-3229-5$

15 Fogh SE, Yu A, Kubicek GJ, Scott W, Mitchell E, Rosato EL and Berger AC: Do elderly patients experience increased perioperative or postoperative morbidity or mortality when given neoadjuvant chemoradiation before esophagectomy? Int J Radiat Oncol Biol Phys 80(5): 1372-1376, 2011. PMID: 21106309. DOI: $10.1016 /$ j.ijrobp.2010.04.055

16 Alderson D, Langley R, Nankivell M, Blazeby J, Griffin M, Crellin A, Grabsch H, Okines A, Goldstein C, Falk S, Thompson J, Krysztopik R, Coxon F, Pritchard S, Langer R, Stenning S and Cunningham D: Neoadjuvant chemotherapy for resectable oesophageal and junctional adenocarcinoma: Results from the UK Medical Research Council randomised OEO5 trial (ISRCTN 01852072). Journal of Clinical Oncology 33(15_suppl): 40024002, 2019. DOI: 10.1200/jco.2015.33.15_suppl.4002

17 Ychou M, Boige V, Pignon JP, Conroy T, Bouché O, Lebreton G, Ducourtieux M, Bedenne L, Fabre JM, Saint-Aubert B, Genève J, Lasser P and Rougier P: Perioperative chemotherapy compared with surgery alone for resectable gastroesophageal adenocarcinoma: an FNCLCC and FFCD multicenter phase III trial. J Clin Oncol 29(13): 1715-1721, 2011. PMID: 21444866. DOI: $10.1200 / J C O .2010 .33 .0597$

18 Van Cutsem E, Moiseyenko VM, Tjulandin S, Majlis A, Constenla M, Boni C, Rodrigues A, Fodor M, Chao Y, Voznyi E, Risse ML, Ajani JA and V325 Study Group: Phase III study of docetaxel and cisplatin plus fluorouracil compared with cisplatin and fluorouracil as first-line therapy for advanced gastric cancer: a report of the V325 Study Group. J Clin Oncol 24(31): 4991-4997, 2006. PMID: 17075117. DOI: 10.1200/JCO.2006.06.8429

19 Shapiro J, van Lanschot JJB, Hulshof MCCM, van Hagen P, van Berge Henegouwen MI, Wijnhoven BPL, van Laarhoven HWM, Nieuwenhuijzen GAP, Hospers GAP, Bonenkamp JJ, Cuesta MA, Blaisse RJB, Busch ORC, Ten Kate FJW, Creemers GM, Punt CJA, Plukker JTM, Verheul HMW, Bilgen EJS, van Dekken H, van der Sangen MJC, Rozema T, Biermann K, Beukema JC, Piet AHM, van Rij CM, Reinders JG, Tilanus HW, Steyerberg EW, van der Gaast A and CROSS study group: Neoadjuvant chemoradiotherapy plus surgery versus surgery alone for oesophageal or junctional cancer (CROSS): long-term results of a randomised controlled trial. Lancet Oncol 16(9): 1090-1098, 2015. PMID: 26254683. DOI: 10.1016/S1470-2045(15)00040-6 
20 Honing J, Smit JK, Muijs CT, Burgerhof JGM, de Groot JW, Paardekooper G, Muller K, Woutersen D, Legdeur MJC, Fiets WE, Slot A, Beukema JC, Plukker JTM and Hospers GAP: A comparison of carboplatin and paclitaxel with cisplatinum and 5-fluorouracil in definitive chemoradiation in esophageal cancer patients. Ann Oncol 25(3): 638-643, 2014. PMID: 24492674. DOI: $10.1093 /$ annonc/mdt589

21 Steber C, Hughes RT, McTyre ER, Soike M, Farris M, Levine BJ, Pasche B, Levine E and Blackstock AW: Cisplatin/5-Fluorouracil (5-FU) versus carboplatin/paclitaxel chemoradiotherapy as definitive or pre-operative treatment of esophageal cancer. Cureus 13(1): e12574, 2021. PMID: 33575139. DOI: 10.7759/cureus.12574

22 Won E and Ilson DH: Management of localized esophageal cancer in the older patient. Oncologist 19(4): 367-374, 2014. PMID: 24664485. DOI: 10.1634/theoncologist.2013-0178

23 Münch S, Pigorsch SU, Devečka M, Dapper H, Weichert W, Friess H, Braren R, Combs SE and Habermehl D: Comparison of definite chemoradiation therapy with carboplatin/paclitaxel or cisplatin/5-fluoruracil in patients with squamous cell carcinoma of the esophagus. Radiat Oncol 13(1): 139, 2018. PMID: 30068371. DOI: 10.1186/s13014-018-1085-Z

24 Courrech Staal EF, Aleman BM, van Velthuysen ML, Cats A, Boot H, Jansen EP, van Coevorden F and van Sandick JW: Chemoradiation for esophageal cancer: institutional experience with three different regimens. Am J Clin Oncol 34(4): 343-349, 2011. PMID: 20562589. DOI: 10.1097/COC.0b013e3181dbbafe

25 van Meerten E, Muller K, Tilanus HW, Siersema PD, Eijkenboom WM, van Dekken H, Tran TC and van der Gaast A: Neoadjuvant concurrent chemoradiation with weekly paclitaxel and carboplatin for patients with oesophageal cancer: a phase II study. Br J Cancer 94(10): 1389-1394, 2006. PMID: 16670722. DOI: $10.1038 /$ sj.bjc.6603134

26 Lorenzen S, Hentrich M, Haberl C, Heinemann V, Schuster T, Seroneit T, Roethling N, Peschel C and Lordick F: Split-dose docetaxel, cisplatin and leucovorin/fluorouracil as first-line therapy in advanced gastric cancer and adenocarcinoma of the gastroesophageal junction: results of a phase II trial. Ann Oncol 18(10): 1673-1679, 2007. PMID: 17660494. DOI: 10.1093/ annonc/mdm269

27 Al-Batran SE, Hartmann JT, Hofheinz R, Homann N, Rethwisch V, Probst S, Stoehlmacher J, Clemens MR, Mahlberg R, Fritz M, Seipelt G, Sievert M, Pauligk C, Atmaca A and Jäger E: Biweekly fluorouracil, leucovorin, oxaliplatin, and docetaxel (FLOT) for patients with metastatic adenocarcinoma of the stomach or esophagogastric junction: a phase II trial of the Arbeitsgemeinschaft Internistische Onkologie. Ann Oncol 19(11): 1882-1887, 2008. PMID: 18669868. DOI: 10.1093/annonc/mdn403

28 Hurria A, Gupta S, Zauderer M, Zuckerman EL, Cohen HJ, Muss H, Rodin M, Panageas KS, Holland JC, Saltz L, Kris MG, Noy A, Gomez J, Jakubowski A, Hudis C and Kornblith AB: Developing a cancer-specific geriatric assessment: a feasibility study. Cancer 104(9): 1998-2005, 2005. PMID: 16206252. DOI: $10.1002 /$ cncr. 21422
29 Hurria A, Togawa K, Mohile SG, Owusu C, Klepin HD, Gross CP, Lichtman SM, Gajra A, Bhatia S, Katheria V, Klapper S, Hansen K, Ramani R, Lachs M, Wong FL and Tew WP: Predicting chemotherapy toxicity in older adults with cancer: a prospective multicenter study. J Clin Oncol 29(25): 3457-3465, 2011. PMID: 21810685. DOI: 10.1200/JCO.2011.34.7625

30 PACE participants., Audisio RA, Pope D, Ramesh HS, Gennari R, van Leeuwen BL, West C, Corsini G, Maffezzini M, Hoekstra HJ, Mobarak D, Bozzetti F, Colledan M, Wildiers H, Stotter A, Capewell A and Marshall E: Shall we operate? Preoperative assessment in elderly cancer patients (PACE) can help. A SIOG surgical task force prospective study. Crit Rev Oncol Hematol 65(2): 156-163, 2008. PMID: 18082416. DOI: 10.1016/ j.critrevonc.2007.11.001

31 Mohile SG, Dale W, Somerfield MR, Schonberg MA, Boyd CM, Burhenn PS, Canin B, Cohen HJ, Holmes HM, Hopkins JO, Janelsins MC, Khorana AA, Klepin HD, Lichtman SM, Mustian KM, Tew WP and Hurria A: Practical assessment and management of vulnerabilities in older patients receiving chemotherapy: ASCO guideline for geriatric oncology. J Clin Oncol 36(22): 2326-2347, 2018. PMID: 29782209. DOI: 10.1200/JCO.2018.78.8687

32 Li Z, Shan F, Wang Y, Zhang Y, Zhang L, Li S, Jia Y, Xue K, Miao R, Li Z and Ji J: Correlation of pathological complete response with survival after neoadjuvant chemotherapy in gastric or gastroesophageal junction cancer treated with radical surgery: A meta-analysis. PLoS One 13(1): e0189294, 2018. PMID: 29370182. DOI: 10.1371/journal.pone.0189294

33 Kelly RJ, Ajani JA, Kuzdzal J, Zander T, Van Cutsem E, Piessen G, Mendez G, Feliciano J, Motoyama S, Lièvre A, Uronis H, Elimova E, Grootscholten C, Geboes K, Zafar S, Snow S, Ko AH, Feeney K, Schenker M, Kocon P, Zhang J, Zhu L, Lei M, Singh P, Kondo K, Cleary JM, Moehler M and CheckMate 577 Investigators: Adjuvant nivolumab in resected esophageal or gastroesophageal junction cancer. N Engl J Med 384(13): 11911203, 2021. PMID: 33789008. DOI: 10.1056/NEJMoa2032125

Received September 26, 2021

Revised October 16, 2021

Accepted October 11, 2021 